\title{
PREVALENCE AND KNOWLEDGE OF CONTACT LENS UPTAKE IN KENYA: A RETROSPECTIVE STUDY
}

\author{
Chikasirimobi Goodhope Timothy', \\ Harun Chemjor Chepkeitany', \\ Diane Wallace Van-Staden ${ }^{3}$, \\ Nathan Shaviya ${ }^{4 i}$
}

${ }^{1} \mathrm{OD}$, Department of Optometry and Vision Science, School of Public Health, Biomedical Science and Technology, Masinde Muliro University of Science and Technology, 190-50100, Kakamega, Kenya orcid.org/0000-0001-5832-484X

${ }^{2} \mathrm{PhD}$, Department of Health Promotion Education, School of Public Health, Biomedical Science and Technology, Masinde Muliro University of Science and Technology, 190-50100, Kakamega Kenya orcid.org/0000-0001-7379-9448 3PhD, Optometry Department, University of Kwa-Zulu Natal, Durban,

South Africa orcid.org/0000-0003-2028-1711 ${ }^{4} \mathrm{PhD}$, Medical Laboratory Department, School of Public Health, Biomedical Science and Technology, Masinde Muliro university of Science and Technology, 190-50100, Kakamega, Kenya orcid.org/0000-0001-7347-3130

\begin{abstract}
:
Background: The use of contact lenses is welcomed for refractive error correction, for therapeutic/diagnostic reasons and for cosmetic reasons, more so in developed countries, unlike in third world countries like Kenya. Aim: The study aim is to determine the prevalence of contact lens use and knowledge about contact lens use in Kenya. Methods: A six (6) years retrospective cross-sectional study (February 2014 - March 2020) was carried out in the Academic Vision center of Masinde Muliro University of Science and Technology, Kakamega, Kenya. A validated tool with open- and closed-ended statements and questions were used to collect data from a calculated sample size (360) that used the
\end{abstract}

'Correspondance: email chikasirimobi@gmail.com, hchemjor@mmust.ac.ke, wallaced@ukzn.ac.za nshaviya@mmust.ac.ke 
Cochrane formula modified by Sullivan and Soe. Participants was selected purposively in accordance to the inclusion criteria, phone contacts, emails, social media platforms were adopted in collecting information from participants and collected data were entered into Excel spreadsheet 2019. Version and Descriptive statistics (frequencies and percentages), was employed in determining prevalence and knowledge of contact lens uptake. Results: Prevalence of contact lens use was very low 4 (1.1\%) and 11 (3.1\%). A large number did not know about contact lenses 347 (96.7\%) and the Knowledge of contact lenses as shown by the mean score was also very low $2.51 \pm 1.7$ indicating very low knowledge of contact lenses. Conclusions: More emphasis should be laid by eye care providers on contact lenses used for refractive, cosmesis and therapeutic uses. Training institutions should also improve their curriculum on contact lens training and dispensing. Policies should allow for the easy establishment of contact lenses manufacturing and marketing industries.

Keywords: prevalence, knowledge, contact lens, contact lens uptake

\section{Introduction}

Contact lenses are medical devices that provide therapeutic, refractive or cosmetic functions.(1) A contact lens is a relatively thin, naturally clear, rigid or soft plastic lens placed directly on the eye in contact with the cornea or sclera, or both, serving as a new anterior surface of the eye.(1) Contact lens wear have also demonstrated certain advantages over spectacles wear. These advantages include freeness to awareness of spectacles, elimination of annoyances caused by misplacing glasses, temple and nose bridge marks.(2) Other advantages are more natural vision, the additional wearing of special aids while watching 3-D movies, wider field of view particularly in driving, improved aesthetics, improved working conditions like in viewing microscopes and reduced sporting injury.(3) There are known disadvantages of contact lenses as well like the challenge of fitting and removal and maintenance. Despite the many advantages of contact lenses over spectacle lenses, their use, in general, is very low in developing countries compared to their high demand in developed countries. $(4,5)$

Worldwide, over 150 million people wear contact lenses. The United States of America (USA) records the highest wearing of contact lenses with 47 million wearers, United Kingdom (UK) records around 4.2 million wearers and other regions followed USA and UK but at a very low wearers rate. $(6,7)$ Contact lenses have seen many advances in their make, uses and purposes. $(8,9)$. Contact lens use results in better visual acuity and vision function when used for the correction of refractive errors.(10) Contact lenses are further useful in the treatment of corneal and scleral conditions while offering a good prognosis. In myopia management, they have proven to be effective in the control of myopia progression.(11) Furthermore, they encourage wear during participation in complex sporting activities, providing less risk, enhanced cosmesis (the preservation, restoration, or bestowing of bodily beauty) and increased contribution to observed ocular 
adnexa modifications and maintenance, as seen in the entertainment and film making industries.(11)

Within the Masinde Muliro University of Science and Technology (MMUST) in Kenya, contact lenses services are available but attract low patronage. Further, there are limited available materials or published studies on the generality of contact lens use whether for refractive errors management, or for medicinal reasons or for cosmesis. There is less patronage of contact lenses by patients accessing the MMUST eye clinic and other eye clinics in Kenya.(12-17) It is against this background that this study is conducted.

Contact lens is an effective management option for the correction of refractive errors alongside spectacles, but also used for management of certain ocular degenerative diseases and for post-surgical interventions. Optometry development generally in Africa and in particular Kenya is at its early stages. The level of specialty training and practices are also still at their foundational stages. Most optometrists and other eye care providers do not mention uptake of contact lenses for the correction of refractive errors to patients visiting eye clinics due to its low patronage and the possible level of optometric training, licensure and confidence/competency exposure.(18-21)

Contact lens manufacturing companies do not have a presence in Kenya and even neighbouring countries of East Africa, leaving uncoordinated and non-regulated contact lens activities to thrive within the region. Thus, no published literature on the use of contact lenses in Kenya could be located at the time of this study, thus it was necessary to determine the prevalence and knowledge of contact lens uptake by patients. This study was performed in the Masinde Muliro University of Science and Technology Academic Vision Centre, Kakamega county in Kenya.

\section{Literature Review}

\subsection{Prevalence of Contact Lens Uptake}

Contact lens use worldwide has gradually increased as evidenced in the rise in its global consumption of about 100 million in 2003 to above 140 million in recent years.,(16) From the estimated world population of 6.1 to 7.5 billion from 2000 to 2020, people needing visual correction is also projected to go from 3.5 billion in year 2000 to 5.3 billion in year 2020 and hence the demand for contact lens use as well.(22,24) The United States of America (USA) has one in every 6 adults (45 million people) using contact lens.(19) In the United Kingdom (UK), contact lens use has risen from 1.6 million users in 1992 to 3.7 million in 2016.(20) China and India are a growing market for contact lens uptake due to incidence of high myopia. It was projected that by the year 2020 from year 2000, of the 2.5 billion populations of these countries, about 1.3 million will be using contact lenses due to the increasing incidence of myopia and presbyopia.(17) Female wearers of contact lenses are more than male wearers with the average age of contact lens wearers as 31 years ( $<18$ years, estimated at $8 \% ; 18-24$ years, $17 \%$ and $\geq 25$ years; $75 \%) .(19)$

From Australia in a population-based study of 19171 interested participants, 1798 were using contact lenses. The study revealed penetrance of contact lens in Australia to be $5.01 \%$ (95\% Confidence Interval CI: $4.78-5.24)$, a prevalence equal to about 650,000 
contact lens wearers between ages 15 - 64 years.(21) Studies from a Singaporean community and Malaysia showed low prevalence of contact lens uptake, $9 \%$ and $7.2 \%$ respectively. $(18,28)$ In the Middle East, studies in Saudi Arabia estimated prevalence of contact lens uptake across the country were $90 \%$ and $70.2 \%$ following a population-based study with sample size of 20415 and of university-based (sample sizes: 1466 and 1065) respectively. $(26,29)$ Prevalence of contact lens uptake in Africa has been shown to be low. Studies to determine the knowledge, penetrance and acceptability of contact lenses exists from studies carried out in Ghana and which showed that prevalence of contact lens uptake is around 17.1\%.(24)(15) The presence of contact lens has been in South Africa for over 30 years but started gaining preeminence some 15 years ago.(25) Studies done in Nigeria could not state the prevalence of contact lens usage but described incidence of corneal ulcers among contact lens wearers and the bacterial and parasitic interactions in contact lens wear. $(32,33)$

Quite outstanding from the above studies is that, contact lens uptake is low in the Asian countries as evidenced from the population of the studies. But in the Middle East, contact lens uptake seemed to be high. In the Asian studies which had more population and sample size, the studies were carried out as population based and which could have influenced the outcome, while in the Middle East, most of the studies were institutional based and gender related. Regarding Africa and contact lens uptake, the prevalence remained low. Existent studies have never been carried out as population based, rather they are institutional based and thus few publications seem to be available when it comes to uptake of contact lens in Africa. The only difference noted was in the Ghanaian case where use of contact lens was obvious since the major presence of publications regarding prevalence of contact comes more from Ghana.

There is no documented evidence regarding prevalence of contact lenses uptake in Kenya as at the time the study was being done. The closest work made public with regard to contact lenses and clinical applications of same was two clinical based survey done at different times about keratoconus and keratoconic patients by Zahra Aly and Walter Yego respectively.(34-36) The increasing prevalence of contact lens uptake is influenced by the rising cases of myopia, need for fashion and ease of living.(1) Current research to enhance visual performances and ocular adnesia repairs and health, also influences contact lens uptake.

Knowledge on contact lens wear in regard to refractive error correction, beautification and other activities is high in the developed countries and specifically in Asian countries where there seems to be documented evidence of higher incidence of refractive errors especially Myopia and Astigmatism. $(8,37,38)$ Studies showed that Contact lens penetration in India was reported as $5.3 \%$ of the target population of 18 million. This is considerably low compared to other Asian countries like China (17\%), Korea (16\%), Malaysia (25\%) and Singapore $(35 \%) .(39,25,40)$ In a study conducted in Iran on awareness and attitude to refractive error correction methods Moghaddam et al., (2013), found out that $80.3 \%, 87 \%$ and $71 \%$ of participants knew nothing about contact lens application, cosmetic contact lenses and therapeutic contact lenses respectively. The study focused on practitioners in the prescription and dispensing of contact lenses.(34) 
Contrary to the Iranian study, a study done in Ghana revealed that $95.8 \%$ of the study participants knew about contact lenses, 35\% of the participants had knowledge of the advantages of using contact lenses, while $65 \%$ knew nothing on any advantages of contact lens use. The Ghanaian study explored basically knowledge of contact lens care and complications and gave negligible attention to the attitudes to contact lens uptake. It was however able to bring out the gender preferences to contact lens uptake being that it showed females wanting contact lenses $28.3 \%$ as against the male, $12.5 \%$. Regarding the source of information on contact lens, $45.3 \%$ mentioned the media as their source.(35) Ghanaians have high knowledge of contact lenses and also use them significantly for refractive error corrections. Out of the 87 case folders reviewed, use of contact lenses for refractive errors correction was highest at $52.9 \%$. In line with other studies, females were shown to use contact lenses more $46(52.9 \%)$ compared to the male $41(47.1 \%)$.(36) The above study shows that the knowledge of contact lens use was appreciable among Ghanaians, but in East Africa of which Kenya is a part, such assertions are not readily available.

\section{Material and Methods}

\subsection{Study Area}

This was a cross-sectional study carried out in Masinde Muliro University of Science and Technology located in Kakamega County, western Kenya, one of the many Universities across Kenya and the only University in Kenya as at the time of the study with an academic vision centre for training eye care practitioners - optometry students particularly. Data was collected at a time by reviewing all clinical records of patients that have attended (from inception- February 2014) and are attending the MMUST AVC until the conclusion of collection of data (March, 2020) for this study. The study population included all records in the Academic Vision Center of all who attended and/or were attending the clinic seeking eye care services.

\subsection{Inclusion Criteria}

Participants included all diagnosed of any refractive error regardless of having been treated or not, those with corneal conditions, those that have conditions that could be managed using contact lenses as an attendee of the AVC within the time that the data was collected.

\subsection{Exclusion Criteria}

Participants unwilling to give consent or who were not assented by their parents and/or guardians to participate in the study were excluded. Participants within the defined age but diagnosed of early presbyopia were also excluded from the study. Participants with no clear contact information and records in their clinic files were also excluded.

The sample size from the given population was calculated using the Cochran formula modified by Sullivan and Soe.(37) The Samples were purposively selected 
allowing patients whose record had all the desired demographical information to be part of the study.

\subsection{Data and Information Collection}

All available clinical records of patients were reviewed; those found to have been diagnosed with refractive errors aged 16 years and above whether treated or not, sorted out. They were contacted by phone calls or sent survey monkey link of the designed questionnaire on email, SMS and other social media platforms. The study was explained to those that were called and same explanation given in the online document. Their willingness to participate in the study was obtained.

\subsection{Data Collection Procedure}

Semi-structured questionnaire consisting of both open-ended and close-ended questions was administered to elicit prevalence and knowledge contact lenses using Likert scale graded and categorical responses. Data collection was done in stages which involved training of assistants, sorting of clinical records and administration of questionnaires/response collection. A total of 1829 available records in the AVC were reviewed within the duration of the study. Purposively, all refractive error cases and related cases to the inclusion criteria were included, totaling 426 . Out of this number, 66 records did not have complete data and were therefore excluded, leaving 360 records for analysis. Four secured telephone lines were used for the purpose of collecting data by the researcher and the trained assistants.

\subsection{Administration of Questionnaires}

The tool used was designed by the researcher in observance to such tool design as acceptable globally since there was no other discovered tool from literature that could comprehensively give the desired data for obtaining reliable and consistent result and which took into consideration all the measures and variables being studied. The tool was piloted for validity and reliability, after which they were administered to identified and consented participants over the phone or email and other social media platforms and their responses automatically sent back to the researcher according to the design of communication. Participants were also allowed about 7 days to go through the sent questionnaires/survey in case they wished to ask questions and/or seek further clarifications.

There were 66 items (questions/statements) divided into Sections A with Part A1 and A2; demographic information (9) items and general eye health status (8) items respectively. Three (3) questions were selected from Section A, part A2 to give the prevalence of contact lens uptake: [which of the following treatment or a combination of treatments were prescribed to you? what treatment was preferred for the diagnosed refractive error? and did you take the proffered treatment?]. Uptake of contact lens is defined as "low uptake" when prevalence was $<50 \%$ and "high uptake" when prevalence was $\geq 50 \%$. Descriptive statistics (frequency and proportions) was applied in analyzing and reporting the findings. PART B1 of Section A is on Knowledge of contact lens which 
covers learned, observed and known traits, which was determined by six (6) items from the tool: [I have heard about contact lenses before; I know what a contact lens is; I know the uses of contact lenses; I have seen and/or held a contact lens before; I know how to fit and remove contact lenses and I am aware of the risks of contact lenses wear]. All items had "Yes", "No" and "Not sure" numerically scored as " 1 ", " 0 " and "- 1 " respectively. Knowledge was categorized as binary into "Good knowledge" when the mean score is $\geq 5$ and "Poor Knowledge" when the mean score is $<5$. It is worthy to note that all responses of "Not sure" scored as "-1", was taken to be uncertain and thus were purposively omitted. The above categorization and classification of knowledge are sequel to existent studies on knowledge in particular on individual level.(45-50) One (1) question on source of information - "I heard about contact lenses for the first time from" on contact lenses elicits also an aspect of knowledge of contact lens. Collated data on prevalence and knowledge, was coded accordingly, entered and cleaned in an excel spread sheet 2019 version. Descriptive statistics (frequencies and percentages), was employed in determining prevalence and knowledge of contact lens uptake.

\section{Results and Discussion}

Table 1 shows the demographic characteristics of respondents. A total of 359(99.7\%) respondents completed the survey, aged 16 to 38 years and more females $210(58.3 \%)$. Educational level showed completed secondary school 213(59.2\%), were students 206(57.2\%) and were not receiving any incomes 295(81.9\%).

Table 1: Demographic Characteristics of Participants

\begin{tabular}{|l|l|c|c|}
\hline Variables & Responses & Frequencies & Percentages \\
\hline \multirow{3}{*}{ Gender } & Males & 149 & 41.7 \\
\cline { 2 - 4 } & Females & 210 & 58.3 \\
\hline \multirow{5}{*}{ Education level } & Completed secondary school & 213 & 59.2 \\
\cline { 2 - 4 } & Certificate/Diploma & 10 & 3.1 \\
\cline { 2 - 4 } & University degree & 45 & 12.5 \\
\cline { 2 - 4 } & Postgraduate (MSc, PhD, postdoc) & 91 & 25.4 \\
\hline Occupation & Student & 206 & 57.2 \\
\cline { 2 - 4 } & Unemployed & 70 & 19.7 \\
\cline { 2 - 4 } & Employed & 59 & 16.4 \\
\cline { 2 - 4 } & Business & 24 & 6.7 \\
\hline \multirow{5}{*}{ Income } & $3,000-10,000$ KES & 6 & 1.7 \\
\cline { 2 - 4 } & $11,000-40,000$ KES & 16 & 4.4 \\
\cline { 2 - 4 } & $41,000-70,000$ KES & 26 & 4.7 \\
\cline { 2 - 4 } & $71,000-100,000$ KES & 294 & 81.9 \\
\cline { 2 - 4 } & Others (student/unemployed) & 17 & \\
\hline
\end{tabular}

Note: Data presented as frequencies (percentages) $(n=360)$

\subsection{General Eye Health Status}

Table 2 shows the general eye health of participants. Those who had their eyes examined less than a year ago 260(72.2\%), others had their eyes examined less than five years ago 
$97(26.9 \%)$ and more than five years ago $3(0.8 \%)$. Nearly all of the participants were told their problem 327(90.8\%) and refractive errors 297 (82.5\%) was diagnosed more. Spectacles were mostly prescribed $284(78.9 \%)$ and were the preferred treatment $313(86.9 \%)$.

Table 2: The General Eye Health Status of the Participants

\begin{tabular}{|c|c|c|c|}
\hline Variable & Response & Frequency & Percentage \\
\hline \multirow[t]{3}{*}{ Last eye check } & $<$ one year previous & 260 & 72.2 \\
\hline & $>1$ year but $<5$ year & 97 & 26.9 \\
\hline & $>5$ years & 3 & 0.8 \\
\hline \multirow{2}{*}{$\begin{array}{l}\text { Were you told } \\
\text { the problem }\end{array}$} & Yes & 327 & 90.8 \\
\hline & No & 33 & 9.2 \\
\hline \multirow{5}{*}{$\begin{array}{l}\text { What was the } \\
\text { problem }\end{array}$} & Refractive error & 297 & 82.5 \\
\hline & Pathological condition & 31 & 8.6 \\
\hline & Not sure & 10 & 2.8 \\
\hline & BV anomaly & 12 & 3.3 \\
\hline & Not told exactly & 10 & 2.8 \\
\hline \multirow{6}{*}{$\begin{array}{l}\text { Were you told that } \\
\text { you have any of } \\
\text { these problems? }\end{array}$} & Myopia & 155 & 43.1 \\
\hline & Hyperopia & 62 & 17.2 \\
\hline & Astigmatism & 81 & 22.5 \\
\hline & Presbyopia & 6 & 1.7 \\
\hline & Not sure & 22 & 6.1 \\
\hline & Other diseases & 34 & 9.4 \\
\hline \multirow[t]{3}{*}{ Mentioned treatment } & Spectacles & 284 & 78.9 \\
\hline & Contact lenses & 4 & 1.1 \\
\hline & Medication & 56 & 15.6 \\
\hline \multirow{3}{*}{$\begin{array}{l}\text { Treatment preferred } \\
\text { for RE }\end{array}$} & Spectacles & 313 & 86.9 \\
\hline & Contact lenses & 11 & 3.1 \\
\hline & Others & 36 & 10.0 \\
\hline \multirow{3}{*}{$\begin{array}{l}\text { Took the preferred } \\
\text { treatment }\end{array}$} & Yes & 250 & 69.4 \\
\hline & No & 109 & 30.3 \\
\hline & Not sure & 1 & 0.3 \\
\hline \multirow{6}{*}{$\begin{array}{l}\text { How was the } \\
\text { treatment }\end{array}$} & Very helpful & 105 & 29.2 \\
\hline & Helpful & 100 & 27.8 \\
\hline & Not sure & 5 & 1.4 \\
\hline & Slightly helpful & 35 & 15.3 \\
\hline & Not helpful at all & 2 & 0.6 \\
\hline & No response & 93 & 25.8 \\
\hline
\end{tabular}

Note: Data presented as frequencies (percentages) $(n=360)$

\subsection{Prevalence of Contact Lens Uptake}

Table 3 presents the prevalence of contact uptake. Contact lens prescription for management of refractive errors and preference was very low 3\% only. Uptake of preferred treatment was high $250(69.4 \%)$ compared to those that did not take the preferred treatment and those that were not sure whether they took the preferred treatment or not $109(30.3 \%)$ and $1(0.3 \%)$ respectively. 
Table 3: Prevalence of Contact Lens Uptake

\begin{tabular}{|l|l|c|c|}
\hline Variable & Response & Frequency & Percentage \\
\hline Prescribed treatment & Spectacles & 284 & 78.9 \\
& Contact lenses & 4 & 1.1 \\
& Medication & 56 & 15.6 \\
& None & 16 & 4.4 \\
\hline Treatment preferred for RE & Spectacles & 313 & 86.9 \\
& contact lenses & 11 & 3.1 \\
& others & 36 & 10.0 \\
\hline Took preferred treatment & Yes & 250 & 69.4 \\
& No & 109 & 30.3 \\
& Not sure & 1 & 0.3 \\
\hline
\end{tabular}

Note: Data presented as frequencies (percentages) $(n=360)$

\subsection{Knowledge about Contact Lenses}

Table 4 and Table 5 represents the knowledge of contact lens and the mean scores for knowledge about contact lens. Figure 1 depicts the source of knowledge of contact lenses. There was $100 \%$ response to all six questions by participants. Source of knowledge about contact lenses for the first time was friends' $217(60.3 \%)$ followed by eye doctors 71(19.7\%). see Figure 1.

Table 4: Response on Knowledge about Contact Lenses

\begin{tabular}{|l|c|c|c|}
\hline Statement & Yes (\%) & No (\%) & Not sure (\%) \\
\hline Had heard about contact lens & $282(78.3)$ & $69(19.2)$ & $9(2.5)$ \\
\hline Know what a contact lens is & $234(65.0)$ & $81(22.5)$ & $45(12.5)$ \\
\hline Know uses of contact lenses & $150(41.4)$ & $121(33.9)$ & $89(24.7)$ \\
\hline Seen/held a contact lens before & $144(40.0)$ & $183(50.8)$ & $33(9.2)$ \\
\hline Know insert and remove contact lenses & $35(9.7)$ & $294(81.7)$ & $31(8.6)$ \\
\hline Aware of the risks of contact lenses & $60(16.7)$ & $264(73.4)$ & $36(9.9)$ \\
\hline
\end{tabular}

Note: Data presented as percentages (frequencies) $(\mathrm{n}=360)$

Respondents' scores are described in Table 5 below showed that Knowledge of contact lens was summarily poor $96.7 \%(n=347)$

Table 5: Description of Mean Scores Obtained from Respondents

\begin{tabular}{|l|c|c|c|c|c|c|}
\hline Ind. variables & $\begin{array}{c}\text { Max. } \\
\text { Obtainable Scores }\end{array}$ & $\begin{array}{c}\text { Min. } \\
\text { Score }\end{array}$ & $\begin{array}{c}\text { Max. } \\
\text { Score }\end{array}$ & Mean \pm SD & \multicolumn{2}{|c|}{ Scores } \\
\hline Knowledge & 6 & 0 & 6 & $2.51 \pm 1.7$ & Good Knowledge & Poor Knowledge \\
\cline { 5 - 7 } & & & & $12(3.3 \%)$ & $347(96.7 \%)$ \\
\hline
\end{tabular}

Note: Ind. $=$ Independent. Cut off marks - mean scores (Knowledge $=2.5)$, Good knowledge scores $(\geq 5)$ and Poor Knowledge scores $(<5) ;(n=360)$ 
Figure 1: Source of Information about Contact Lenses for the First Time

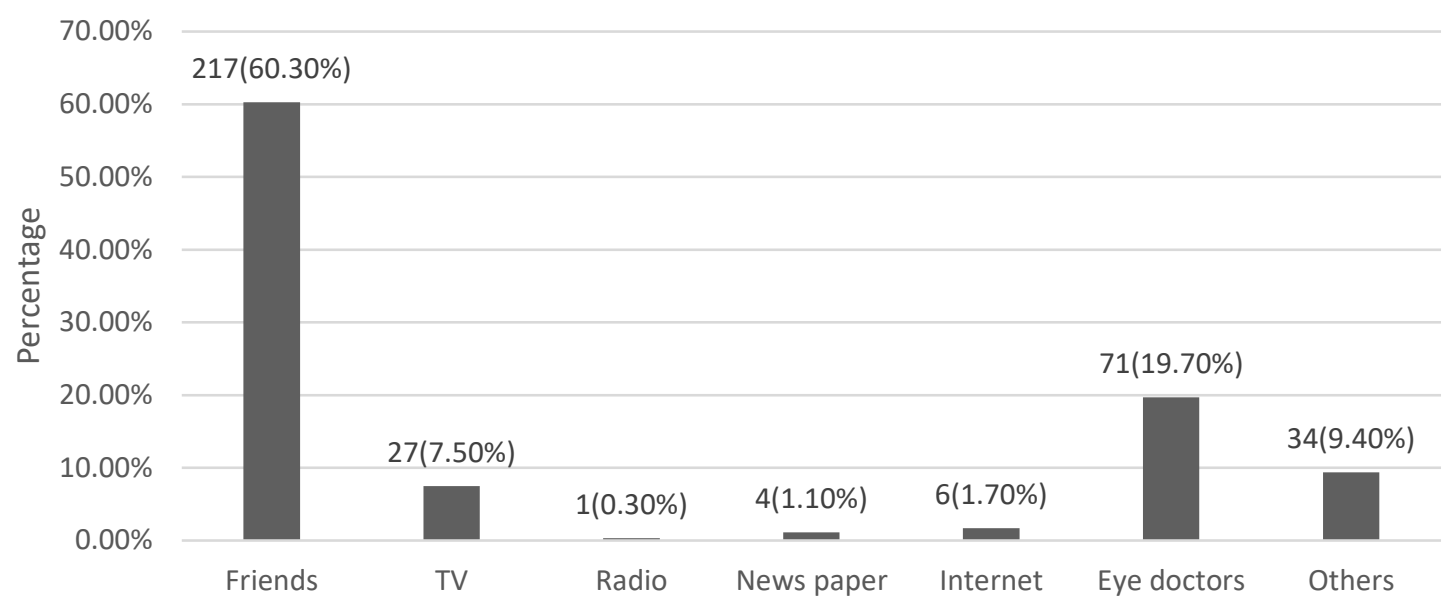

Note: Data presented as frequencies (percentages) $(n=360)$.

\subsection{Demographic Characteristics}

There were more females in this study with mean age $22.85 \pm 4.32$. Participants were educated up to secondary school levels with most of them unemployed and without income. The finding in this study is supported by other global trends in similar studies as shown in a study in Calabar Nigeria on Contact lens,(27) and another study Irfan et al., (2019) reported from Karachi, Pakistan that also showed more females of age 16 to 25 years.(40) Other studies were done in Malaysia with the female to male ratio of 7:1 and all students of age 20 to 25 years.(14) Similar trends were observed in Ghana, Spain, Turkey, India and Saudi Arabia from where studies on contact lenses were reported.(41,35,42,43) Only one study done by Kumar in India had more male participants (44) and a Saudi Arabia study that was population based had participants from 10 years of age to 80 years.(45) Most studies were done in the universities and/or secondary school. The drive to look different could be associated with the constant dominating of participation in these studies by the younger generation, since they will to have a new look and to conform to demand by the immediate environment.

\subsection{Prevalence of Contact Lens Uptake in Correction of Refractive Errors}

From this study, it is clear that prevalence of contact lens uptake was low. The prescription of contact lenses as a management option was low, thus, the uptake was also low which is seen to be attributable to the fact that eye care practitioners did not prescribe contact lens oftentimes. In a country like Singapore, following a population-based survey of one of its electoral communities, the prevalence of uptake of contact lenses for refractive errors management was low 9.0\%.(46) Likewise, in Malaysia, the prevalence of contact lens uptake was 7.2\%,(47) which is also low agreeing with this study. Prevalence, use and sale of contact lenses in Riyadh, Saudi Arabia among female university students showed a high uptake of contact lenses $70.2 \%$ but interestingly, the study revealed that the report is not representative of the prevalence of contact lens uptake in Saudi Arabia.(4) A similar study in Jeddah also among female students showed the prevalence of contact lens uptake to be $40.5 \%$, compared to the uptake of same in Riyadh Saudi 
Arabia. These variances arise possibly due to the environmental influence in these areas - that is the university environment.(5) Notably in Ghana, following studies to determine prevalence of contact lens uptake, report showed low uptake as well but agreeing with other studies about the dominance of young females in contact lens uptake and for cosmetic reasons and comfort being the motivating factor for uptake.(24,15) The variation in contact lens uptake could possibly be influenced by the location of most studies Universities. Other influences that could be affecting low prevalence of contact lens as evidenced in Kenya, is the absence of contact lens manufacturers and distributors.

\subsection{Knowledge on Contact Lens Uptake}

Knowledge of contact lenses could be broadly classified into "Good knowledge" and "Poor Knowledge" to summarize the findings. This broad classification conceals the fact about described knowledge of contact lenses. Knowledge about contact lenses goes beyond just knowing, handling and usage to identifying materials of make and types of contact lenses and their usages, source of information about contact lenses for the first time and functions of contact lenses. $(49,50)$

In a population-based study in Goan India, knowledge considered as awareness of a contact lens in any dimension, showed low/poor knowledge.(51) Agreeing with this study, the Goan study confirmed very poor knowledge of the risks of contact lens by participants. About $71.4 \%$ and $4.9 \%$ were neither not aware of contact lens risks nor were not sure respectively regarding the risks of a contact lens. The Goan study in contradiction to this study stated that $59 \%$ did not know about contact lens at all, while this study showed that only $19.2 \%$ and $2.5 \%$ did not know and were not sure of contact lens. Tchiakpe et al., (2017), confirmed good knowledge of contact lens 95.8\%, Tajunisah and his team also reported good knowledge of contact lens among medical students in Malaya and in Karachi Pakistan a good knowledge (97.0\%) of contact lens was reported to $(14,35,40)$ disagreeing to this study showing $78.3 \%$.

Knowledge on the risks of contact lens, which includes over-wear syndrome and acanthaemoba infection was high in the studies carried out among university student in Malaya by Tajunisah.(14) Similar results were reported in Bangalore (50.8\%) and among Medical students $(92.5 \%)$ by Ibrahim. $(52,53)$ Contrary to those studies and in agreement with this study, an Iranian population-based study reported no knowledge to contact lens risks $80.3 \%$.(34) These variations as shown in knowledge results could be attributed to small sample size used in these studies, the fact that the studies were looking at contact lens wearers already and the study area of each study.

\subsection{Limitation of Study}

Due to the nature of this study, one major challenge encountered is the agreeableness of participants over phone. The cut-across divide in individual understanding posed a big challenge. The research assistants (final year optometry students) under the direct observation of the lead researcher, in an effort to cushion these challenges was able to communicate to each participant in a language that they fully understood through phone interaction and before sending out the survey by email to willing participants. 


\title{
5. Recommendations
}

Eye care practitioners are encouraged to open up to patients and inform them about contact lenses and their uses, benefits and disadvantages. Also, adequate trainings should be at the disposal of eye care practitioners. More practitioners should get in touch with manufacturers to have these devices available in their practices, thus enabling its accessibility to every patient diagnosed with refractive error. Finally, there is need to conduct a national survey on contact lens in Kenya.

\section{Conclusion}

The prevalence of and knowledge about contact lens is very low and thus poor. This is seen to happen as contact lens was not prescribed in most of the diagnosis and thus it was not the treatment of preference by the Patients. This could also be as a result of the fact that prescription of contact lens was not actually undertaking by eye care specialists during visit by the patients.

\section{Acknowledgements}

Thanks to Dr. Levi Uchechukwu Osuagwu, for performing the statistical analysis. All the authors contributed immensely to this article. Chikasirimobi Goodhope Timothy proposed and conceptualized the title, performed the writing task and completion of the study. Dr. Harun Chemjor C and Dr. Diane Wallace Van-Staden supervised the study and Dr. Nathan Shaviya performed the statistical analysis and review of the document.

\section{Funding Statement}

No funding was received for this study.

\section{Conflict of Interest Statement}

There is no competing interest or person gratification from any of the Authors regarding this work

\begin{abstract}
About the Authors
Chikasirimobi Goodhope Timothy is a Doctor of Optometry with specialty in Contact lens and Anterior segments and having special interest in public health and eye health care. He is an astute researcher, with publication in eye care, COVID-19 and public health. Also, he mentors Optometry students in Masinde Muliro University of Science and Technology, Jomo Kenyatta University of Science and Technology, all in Kenya and a preceptor with University of Cape Coast, Cape Coast, Ghana, where he lectures BSc and BOptom to Doctor of Optometry (OD) degree.

Dr. Harun Chemjor Chepkeitany is the Chairman of Department of Public Health Education and lecturer in the School of Public Health, Biomedical Sciences and technology, Masinde Muliro University of Science and Technology, Kakamega, Kenya.
\end{abstract}


He holds his $\mathrm{PhD}$ in the same field and has to his accolades various publications and supervision of postgraduate students.

Dr. Diane Wallace Van-Staden is the academic leader and Senior Lecturer in the department of Optometry and Vision Science, University of Kwa-Zulu Natal, South Africa. She is a renowned Optometrist, Scholar, researcher, Academician, mentor and great administrator. She holds a PhD in Public health. So many articles are accredited to her dexterity and research expertise and which are found across scholarly platforms globally.

Dr. Nathan Shaviya holds a PhD in Medical Genetics and also a reputable Statistician and Senior Lecturer. He is the Head of Examination Coordination and Postgraduate Students coordinator in the School of Public Health, Biomedical science and Technology, Masinde Muliro University of Science and Technology, Kakamega, Kenya. He is also a seasoned and acclaimed researcher in the field of public health and across the health care field.

\section{References}

1. ElShaer A. Contact Lenses: Clinical Evaluation, Associated Challenges and Perspectives. Pharm Pharmacol Int J [Internet]. 2017;5(3). Available from: http://medcraveonline.com/PPIJ/PPIJ-05-00119.php

2. $\quad$ Essilor. Fitting Issues Fitting and Dispensing Progressive Lenses. 2014.

3. McMonnies CW. 50 Reasons for Wearing Contact Lenses. Cont Lens Ant Eye [Internet]. 2011;(34):241-8. Available from: http://www.visioncareresearch.com/cms-assets/documents/83941-646140.50.pdf

4. Abahussin M, AlAnazi M, Ogbuehi KC, Osuagwu UL. Prevalence, use and sale of contact lenses in Saudi Arabia: Survey on university women and non-ophthalmic stores. Contact Lens Anterior Eye. 2014;37(3):185-90.

5. Cope JR, Collier SA, Rao MM. Contact Lens Health Week - Contact Lens Wearer Demographics and Risk Behaviors for Contact Lens-Related Eye Infections United States, 2014. 2015;64(32).

6. Stapleton F, Keay L, Jalbert I, Cole N. The epidemiology of contact lens related infiltrates. Vol. 84, Optometry and Vision Science. 2007. p. 257-72.

7. Yeung KK, Yee CS. Trend-Setting: Global Lens Distribution: The worldwide use of contact lenses as a form of vision correction gives us a glimpse into the prescribing trends of other countries. [Internet]. Review of Cornea and Contact lenses. 2011 [cited 2020 May 31]. Available from: https://www.reviewofcontactlenses.com/article/trend-setting-global-lensdistribution

8. Key JE. Development of Contact Lenses and Their Worldwide Use. Eye Contact Lens Sci Clin Pract [Internet]. 2007 Nov [cited 2019 Jul 28];33(Supplement):343-5. Available from: http://www.ncbi.nlm.nih.gov/pubmed/17975417

9. Siviglia N. History of Contact Lenses. Lancaster, PA; 2010. p. 1-9. 
10. Tomi A, Preda C, Nedelcu A, Goicea D. [Advantages and disadvantages of contact lenses in the correction of ametropia]. Oftalmologia. 2005;49(2):82-9.

11. Tay SA, Farzavandi S, Tan D. Interventions to Reduce Myopia Progression in Children. Strabismus. 2017 Jan;25(1):23-32.

12. Nyamai. Prevalence, Knowledge, Attitude and Practice on Refractive error among Students attending Public High Schools in Nairobi County. University of Nairobi; 2016.

13. Leo SW. Current approaches to myopia control. Curr Opin Ophthalmol [Internet]. 2017 May 1 [cited 2017 Nov 11];28(3):267-75. Available from: https://insights.ovid.com/crossref?an=00055735-201705000-00011

14. Tajunisah I, Ophth M, Reddy SC, Phuah SJ. Knowledge and practice of contact lens wear and care among medical students of University of Malaya. Med J Malaysia [Internet]. 2008 Aug [cited 2019 Jun 28];63(3):207-10. Available from: http://www.ncbi.nlm.nih.gov/pubmed/19248691

15. Ocansey S, Ovenseri Ogbomo G, Abu EK, Morny EKA, Adjei-Boye O. Profile, knowledge, and attitude of contact lens users regarding contact lens wear in Ghana. Contact Lens Anterior Eye [Internet]. 2019 Apr 1 [cited 2020 Aug 18];42(2):170-7. Available from: https://pubmed.ncbi.nlm.nih.gov/30415960/

16. Hui A. Where Have All of the Contact Lens Wearers Gone? [Internet]. Contact lens spectrum. 2019 [cited 2020 Aug 18]. Available from: https://www.clspectrum.com/issues/2019/july-2019/where-have-all-of-thecontact-lens-wearers-gone

17. Holden Brien, Stretton S, Evans K, Sweeney D. Contact Lens Spectrum - Contact Lenses: Where Now and Where to? [Internet]. Contact Lens Spectrum. 2003 [cited 2020 Aug 19]. p. 1-5. Available from: https:/www.clspectrum.com/issues/2003/january-2003/contact-lenses-wherenow-and-where-to

18. Adelson JD, A Bourne RR, Svitil Briant P, Flaxman SR, B Taylor HR, Jonas JB, et al. Causes of blindness and vision impairment in 2020 and trends over 30 years, and prevalence of avoidable blindness in relation to VISION 2020: the Right to Sight: an analysis for the Global Burden of Disease Study. Lancet Glob Heal [Internet]. 2021 [cited 2021 Jun 27];9:e144-60. Available from: http://www.anglia.ac.uk/verigbd

19. CDC.com. Fast Facts I Contact Lenses I CDC Healthy contact lens wear and care [Internet]. Centre for disease control and prevention. 2018 [cited 2020 Aug 21]. p. 1-2. Available from: https://www.cdc.gov/contactlenses/fast-facts.html

20. Ai-Salameh NS, Abahussin M, Al-Garni AE, Althagafi MA, Alanazi M. Contact lenses in Saudi Arabia: prevalence and characteristics of wear and care. Int J Sci Eng Res [Internet]. 2017 [cited 2021 Jul 15];8(8). Available from: http://www.ijser.org

21. Edwards K, Lisa Keay Ba, Thomas Naduvilath Bo, Stapleton F, Faao Mco. The penetrance and characteristics of contact lens wear in Australia. Clin Exp Optom 
[Internet]. 2014 [cited 2019 May 5];97:48-54. Available from: https://onlinelibrary.wiley.com/doi/pdf/10.1111/cxo.12078

22. Teo L, Lim L, Tan DTH, Chan TK, Jap A, Ming LH. A survey of contact lens complications in Singapore. Vol. 37, Eye and Contact Lens. 2011. p. 16-9.

23. Alobaidan OS, Alkhalifah MK, AlSayegh AA, Alhumaid FA, Ashammery AS, Alghamdi K, et al. Knowledge and practice regarding contact lens among Saudi urban contact lens users. Saudi J Ophthalmol Off J Saudi Ophthalmol Soc [Internet]. 2018 Apr 1 [cited 2020 Aug 19];32(2):93-6. Available from: http://www.ncbi.nlm.nih.gov/pubmed/29942175

24. Abokyi S, Manuh G, Otchere H, Ilechie A. Knowledge, usage and barriers associated with contact lens wear in Ghana. Contact Lens Anterior Eye. 2017 Oct 1;40(5):329-34.

25. Oduntan AO, Ranchod H, Baker R. Contact lenses in South Africa: An overview. Int Contact Lens Clin [Internet]. 1998 May 1 [cited 2020 Aug 19];25(3):73-6. Available

from: http://www.contactlensjournal.com/article/S0892896798000170/fulltext

26. Oghre E, Asonye C. Prevalence of corneal ulcer among contact lens wearers in Nigeria. Glob J Med Sci [Internet]. 2004 May 21 [cited 2020 Aug 19];2(2):127-30. Available from: https://www.ajol.info/index.php/gjms/article/view/10121

27. Ibanga AA, Nkanga DG, Etim BA, Echieh IC. Awareness of the Practice and Uses of Contact Lens amongst Students in a Nigerian Tertiary Institution. Sch J Appl Med Sci (SJAMS [Internet]. 2017 [cited 2020 May 30];5(8B):3111-6. Available from: http://saspublisher.com/sjams/www.saspublisher.com

28. Rashid ZA, Millodot M, Evans KSE. Characteristics of keratoconic patients attending a specialist contact lens clinic in Kenya. Middle East Afr J Ophthalmol. 2016 Oct 1;23(4):283-7.

29. Kibet Yego W, Raquel Moodley V. Visual Acuity and Refractive Error Improvement in Keratoconic Patients: A Low-Income Context Management Perspective. 2020 [cited 2020 Aug 23]; Available from: http://doi.org/10.2147/OPTO.S258905

30. Morgan P, Woods CA, Tranoudis I, Helland M. International Contact Lens Prescribing In 2016 [Internet]. Contact lens spectrum. 2017 [cited 2020 Aug 19]. Available from: https://www.researchgate.net/publication/312164301_INTERNATIONAL_CONT ACT_LENS_PRESCRIBING_IN_2016

31. Kumari R, Chaudhry M, Sharma D. Conversion to Contact Lens from SpectaclesA Study About the Practitioner' S Influence / Initiative. 2017;13(1):131-6.

32. Cope JR, Collier SA, Rao MM, Chalmers R, Mitchell GL, Richdale K, et al. Contact Lens Wearer Demographics and Risk Behaviors for Contact Lens-Related Eye Infections - United States, 2014 [Internet]. Morbidity and Mortality Report. 2015 [cited 2020 Aug 19]. p. 865-70. Available from: https://www.cdc.gov/MMWr/preview/mmwrhtml/mm6432a2.htm 
33. Wire Business. Global Contact Lenses Market Review and Outlook, 2016-2019 \& 2027 - ResearchAndMarkets.com I Business Wire [Internet]. 2019 [cited 2020 Aug 19]. Available

from: https://www.businesswire.com/news/home/20191126005460/en/Global-ContactLenses-Market-Review-Outlook-2016-2019

34. Moghaddam S, Ak R, Pourmazar R, Gohary I. Awareness and Attitude toward Refractive Error Correction Methods: A Population Based Study in Mashhad. 2013;

35. Tchiakpe MP, Nhyira SA, Nartey A. Awareness and Response of Undergraduate Spectacle Wearers to Contact Lens Usage. J Clin Ophthalmol Optom [Internet]. 2017;1(1):7. Available from: http://www.scienceinquest.com/openaccess/pdf/jcoo/awareness-and-response-of-undergraduate-spectacle-wearers-tocontact-lens-usage.pdf

36. Ocansey S, Ovenseri Ogbomo G, Abu EK, Morny EKA, Adjei-Boye O. Profile, knowledge, and attitude of contact lens users regarding contact lens wear in Ghana. Contact Lens Anterior Eye [Internet]. 2019 Apr 1 [cited 2020 Aug 19];42(2):170-7. Available from: https://pubmed.ncbi.nlm.nih.gov/30415960/

37. Sullivan KM, Soe MM. Sample Size for a Cross-Sectional, Cohort, or Clinical Trial Studies Sample Size for Cross-Sectional \& Cohort Studies \& Clinical Trials. 2007;

38. Abhary K, Adriansen K, Begovac F, Djukic D, Qin B, Spuzic S, et al. Some basic aspects of knowledge. Procedia Soc Behav Sci [Internet]. 2009 [cited 2019 Apr 9];1:1753-8. Available from: www.sciencedirect.com

39. Ekpenyong BN, Osuagwu UL, Miner CA, Ovenseri-ogbomo GO, Abu EK, Goson PC, et al. Knowledge, Attitudes, and Perceptions of COVID- 19 among Healthcare and Non-Healthcare Workers in Sub-Saharan Africa: A Web-Based Survey. 2021;1-13.

40. Irfan R, Memon RS, Shaikh MY, Khalid I, Shakeel N, Tariq E. Knowledge and attitude of youth towards contact lenses in Karachi, Pakistan. J Glob Heal Reports. 2019 Sep 5;3:e2019042.

41. Zeri F, Durban JJ, Hidalgo F, Gispets J. Attitudes towards contact lenses: A comparative study of teenagers and their parents. Contact Lens Anterior Eye. 2009;33:119-23.

42. Segnor T, Alkibay S, Sertoglu AE, Kurna SA. Survey to Determine Perceptions and Practices in Contact Lens Use and Identify Key Features of Safe Use Education. Turk J Ophthalmol. 2018;48:288-94.

43. Alswailmi FK. Contact Lenses: Perception, Knowledge and Practice Among Female Students in Hafr Al-Batin University. 2019 May 7 [cited 2021 Aug 2]; Available from: https://zenodo.org/record/2671785

44. Venkatesh Kumar T, Ranjee PH, Farokh SE. Knowledge, attitude and practice of medical students using contact lenses. Indian J Clin Exp Ophthalmol [Internet]. 2017 [cited 2019 Jun 25];3(3):333. Available from: http://oaji.net/articles/2017/18731508230109.pdf 
45. Jazaa Alharbi A, Abdullah Sarriyah JF. Beliefs, attitude and knowledge of contact lens wear and care among Saudi Arabia population. Clin Diagnostic Pathol. 2019;3(1).

46. Lee YC, Lim CW, Sam SM, Koh D. The prevalence and pattern of contact lens use in a Singapore community. CLAO J. 2000;26:21-5.

47. Bhandari M, Rou HP, Hung PP. Habits of contact lens wearers toward lens care in Malaysia. Med J Malaysia. 2012;67(3):274-7.

48. Ibrahim NK, Seraj H, Khan R, Baabdullah M, Reda L. Prevalence, habits and outcomes of using contact lenses among medical students. Pakistan J Med Sci. 2018 Nov 1;34(6):1429-34.

49. Sulley A, Young G, Hunt C. Factors in the success of new contact lens wearers. Contact Lens Anterior Eye. 2017 Feb 1;40(1):15-24.

50. Moreddu R, Vigolo D, Yetisen AK. Contact Lens Technology: From Fundamentals to Applications. Vol. 8, Advanced Healthcare Materials. Wiley-VCH Verlag; 2019. p. 1900368.

51. Usgaonkar UPS, Tambe P. Awareness and Attitude toward Refractive Error Correction Methods, Among Goan Population. J Dent Med Sci [Internet]. 2018 [cited 2019 Jun 28];17(3):04-10. Available from: www.iosrjournals.org

52. Sujatha V, Pandu S. Knowledge, Attitude and Practice of Contact Lens Users Among Medical College Students in Bangalore. J Evid Based Med Healthc [Internet]. 2015;2(39):6378-82. Available from: http://www.jebmh.com/data_pdf/Sujatha - 2.pdf

53. Ibrahim N, Seraj H, Khan R, Baabdullah M, Reda L. Prevalence, habits and outcomes of using contact lenses among medical students. Pak J Med Sci [Internet]. 2018 [cited 2020 May 31];34(6):1429-34. Available from: www.pjms.com.pk1429 
Creative Commons licensing terms

Author(s) will retain the copyright of their published articles agreeing that a Creative Commons Attribution 4.0 International License (CC BY 4.0) terms will be applied to their work. Under the terms of this license, no permission is required from the author(s) or publisher for members of the community to copy, distribute, transmit or adapt the article content, providing a proper, prominent and unambiguous attribution to the authors in a manner that makes clear that the materials are being reused under permission of a Creative Commons License. Views, opinions and conclusions expressed in this research article are views, opinions and conclusions of the author(s). Open Access Publishing Group and European Journal of Public Health Studies shall not be responsible or answerable for any loss, damage or liability caused in relation to/arising out of conflicts of interest, copyright violations and inappropriate or inaccurate use of any kind content related or integrated into the research work. All the published works are meeting the Open Access Publishing requirements and can be freely accessed, shared, modified, distributed and used in educational, commercial and non-commercial purposes under a Creative Commons Attribution 4.0 International License (CC BY 4.0). 